Tersedia online di: http://ejournal-balitbang.kkp.go.id/index.php/bawal
e-mail:bawal.puslitbangkan@ @mail.com
BAWAL WIDYA RISET PERIKANAN TANGKAP
Volume 12 Nomor 1 April 2020
p-ISSN: 1907-8226
e-ISSN: 2502-6410
BAWAL
Nomor Akreditasi Kementerian RISTEKDIKTI: 21/E/KPT/2018

\title{
DINAMIKA POPULASI DAN STATUS PEMANFAATAN UDANG TIGER (Penaeus monodon Fabricius 1798) DI PERAIRAN TARAKAN, KALIMANTAN UTARA
}

\section{POPULATION DYNAMIC AND EXPLOITATION STATUS OF TIGER PRAWN (Penaeus monodon Fabricius 1798) IN TARAKAN WATERS, NORTH KALIMANTAN}

Umi Chodrijah*1, Ria Faizah ${ }^{2}$ dan Tirtadanu' ${ }^{1}$

${ }^{1}$ Peneliti pada Balai Riset Perikanan Laut - Jl. Raya Bogor KM 47, Nanggewer - Cibinong, Bogor, Jawa Barat, Indonesia ${ }_{2}^{2}$ Peneliti pada Pusat Riset Perikanan - Gedung Balitbang KP II, Jl. PAsir Putih 2 Ancol Timur, Jakarta Utara, Indonesia Teregistrasi I tanggal: 22 Januari 2020; Diterima setelah perbaikan tanggal: 24 Juli 2020; Disetujui terbit tanggal: 03 Agustus 2020

\begin{abstract}
ABSTRAK
Udang tiger (Penaeus monodon Fabricius 1798) di Tarakan merupakan salah satu komoditas ekspor dan sudah dimanfaatkan cukup lama serta memiliki permintaan dan nilai ekonomis yang tinggi. Penelitian dinamika populasi dan status pemanfaatan udang tiger di perairan Tarakan dan sekitarnya dilakukan untuk mengevaluasi status stok sumberdaya udang agar pengelolaannya dapat berkelanjutan. Penelitian ini dilakukan pada bulan Januari-November 2016 dengan metode survey. Status pemanfaatan diduga berdasarkan laju eksploitasi dan estimasi rasio pemijahan berbasis data panjang $(L B-S P R)$. Hasil pengamatan menunjukkan udang tiger memiliki panjang karapas asimptotik ( $\mathrm{CL}_{\infty}$ ) sebesar $65,45 \mathrm{~mm}$, laju pertumbuhan $(\mathrm{K})$ sebesar 1,55/tahun dan nilai $\mathrm{t}_{0}$ sebesar -0,20/tahun sehingga diperoleh persamaan pertumbuhan Von Bertalanffy CLt $=65,45\left(1-\mathrm{e}^{-1,55(t+-0,20)}\right)$. Laju mortalitas total (Z) sebesar 6,56/ tahun, mortalitas alami (M) sebesar 1,95/tahun, mortalitas penangkapan (F) sebesar 4,62/tahun dan tingkat pemanfaatan (E) sebesar 0,70/tahun. Tingkat pemanfaatan udang tiger di perairan Tarakan lebih besar dari tingkat pemanfaatan optimal sehingga disarankan untuk menurunkan upaya sebesar $40 \%$ dari upaya saat ini.
\end{abstract}

Kata Kunci: Dinamika populasi; status pemanfaatan; udang tiger; Tarakan

\begin{abstract}
Tiger prawn (Penaeus monodon Fabricius 1798) was one of the export commodity and had been exploited for longtime ago so it was necessary to study about its population parameters and exploitation status for its sustainable management. This research aimed to study about the population parameters and exploitation status of tiger prawn. The research were carried out from January to November 2016 using survey method and the enumeration programme. The growth parameters were based on the Modal Progression Analysis. Exploitation status was estimated based on length based spawning potential ratio (LB-SPR). The results showed that the asymptotic length $\left(C L_{\infty}\right)$ was $65.45 \mathrm{~mm}$, the growth rate $(K)$ was 1.55 /year and $=t_{0}$ was $-0,20$ /year so Von Bertalanffy Growth Model was CLt $=65.45\left(1-e^{-1.55(t+-0.20)}\right)$. Total mortality $(Z)$ was $6.56 /$ years, natural mortality was 1.95/years and fishing mortality was 4.62/years. The exploitation rate (E) was 0,70/years. The exploitation rate now is higher then the optimal level so it is recommended to reduce $40 \%$ of the current efforts.
\end{abstract}

Keywords: Population dynamics; exploitation status; tiger shrimp; Tarakan

Korespondensi penulis:

e-mail: umi_chodriyah@yahoo.co.id

Telp. +62 812-8434-045

DOI: http://dx.doi.org/10.15578/bawal.12.1.2020.11-17

Copyright @ 2020 , BAWAL WIDYA RISET PERIKANAN TANGKAP (BAWAL) 


\section{PENDAHULUAN}

Perairan Tarakan, Kalimantan Utara merupakan bagian Wilayah Pengelolaan Perikanan (WPP) 716 mempunyai potensi udang selain perikanan nomei yang telah menjadi ikon di kota Tarakan. Salah satu jenis udang yang menjadi target utama oleh nelayan di perairan Tarakan adalah udang tiger (Penaeus monodon) sebagai komoditas ekspor yang dikirim langsung ke Tawau, Malaysia bersama dengan udang jerbung.

Produksi udang tiger di perairan Indonesia berfluktuatif dengan total produksi antara tahun 2005-2016 berkisar antara $24.637-42.036$ ton. Menurunnya produksi udang tiger pada 2015 dan 2016 diduga disebabkan oleh menurunnya upaya penangkapan sejak diberlakukannya pelarangan trawl di tahun 2015. Produksi udang tiger di tahun 2016 di perairan WPP 716 (Laut Sulawesi) sebesar 726 ton atau memberikan kontribusi sebesar 2,6\% dari produksi total udang tiger di Indonesia. Produksi udang tiger di Laut Sulawesi pada tahun 2015 juga mengalami penurunan sebesar $40 \%$ dari tahun sebelumnya di tahun 2014 (Direktorat Jenderal Perikanan Tangkap, 2016).

Penggunaan alat tangkap trawl yang kurang selektif dan cenderung merusak lingkungan menyebabkan diberlakukannya Peraturan Menteri Kelautan dan Perikanan Republik Indonesia No. 2/ Permen-KP/ 2015 tentang larangan penggunaan alat tangkap pukat hela (termasuk trawl) dan pukat tarik di seluruh Wilayah
Pengelolaan Perikanan (WPP) Indonesia. Penangkapan udang tiger di Tarakan yang sebelumnya menggunakan lampara dasar kemudian banyak yang beralih menggunakan jaring tiga lapis sejak diberlakukannya peraturan pelarangan trawl di tahun 2015. Jaring tiga lapis merupakan salah satu alat tangkap yang cukup selektif dalam menangkap udang namun penggunaannya yang sangat intensif juga dapat memberikan dampak bagi kelestarian sumberdaya udang. Berkaitan dengan hal tersebut, perlu dilakukan kajian dinamika populasi dan tingkat pemanfaatan udang tiger (Penaeus monodon) sebagai salah satu upaya dalam merancang strategi pengelolaan perikanan udang tiger yang berkelanjutan di perairan Tarakan. Tujuan dari penelitian ini adalah untuk mengetahui dinamika populasi dan status pemanfaatan udang tiger di perairan Tarakan sebagai salah satu dasar dalam pengelolaan udang tiger yang bertanggung jawab.

\section{METODOLOGI \\ Pengambilan Sampel}

Penelitian dilakukan di perairan Tarakan, Kalimantan Utara pada Januari-November 2016. Pengukuran panjang karapas udang tiger ( $P$. monodon) sebanyak 2.208 ekor dilakukan saat observasi di lapangan dan melalui pengukuran oleh enumerator tiap bulan. Sampel udang tiger (Penaeus monodon) diperoleh dari hasil tangkapan nelayan trammel net yang tertangkap di sekitar perairan Barat Selumit Pantai (Gambar 1).

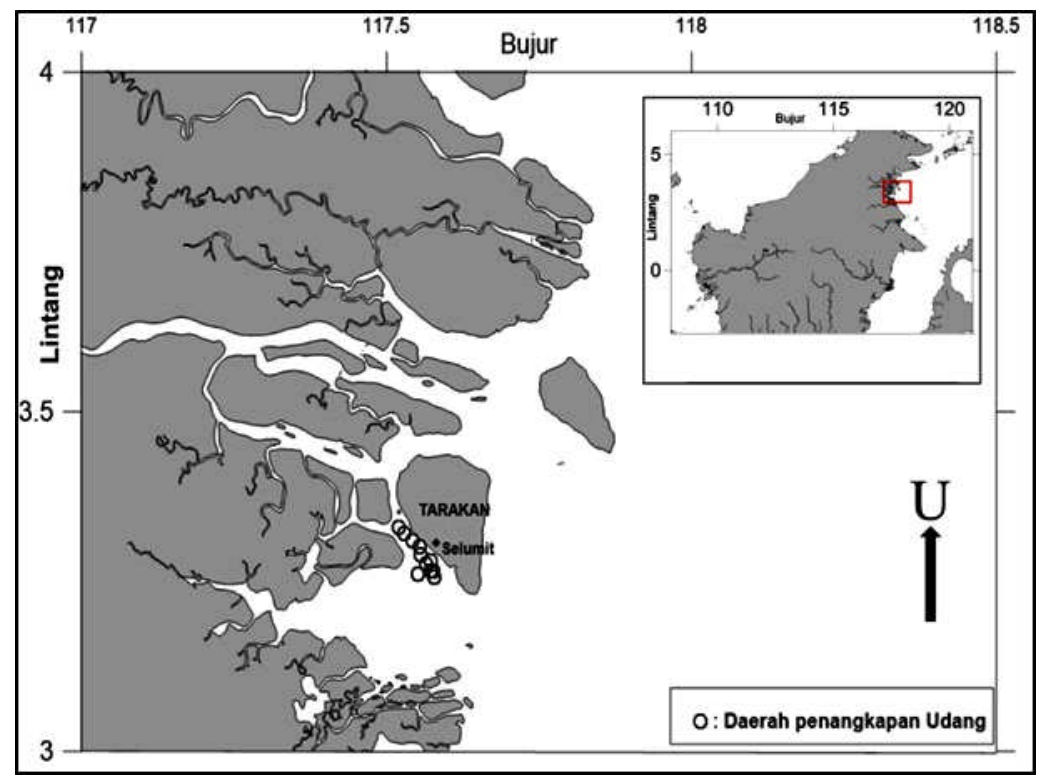

Gambar 1. Daerah penangkapan udang di perairan Tarakan.

Figure 1. Fishing ground of shrimps in Tarakan Waters. 


\section{Analisis Data}

Analisis data yang dilakukan pada penelitian ini adalah analisis pertumbuhan meliputi panjang karapas asimptotik $\left(\mathrm{CL}_{\infty}\right)$ dan laju pertumbuhan $(\mathrm{K})$, analisis laju mortalitas dan laju eksploitasi E dan estimasi rasio pemijahan (SPR).

Pola pertumbuhan udang yang diteliti diasumsikan mengikuti model pertumbuhan von Bertalanffy (Sparre \& Venema, (1992):

$C L_{t}=C L \infty\left[1-e^{-K\left(t-t_{0}\right)}\right]$

$\mathrm{CL}_{\mathrm{t}}$ adalah panjang karapas udang saat umur $\mathrm{t}, \mathrm{CL}_{\infty}$ adalah panjang karapas maksimum secara teoritis (panjang karapas asimptotik), $\mathrm{K}$ adalah laju pertumbuhan dan $\mathrm{t}_{0}$ adalah umur teoritis saat panjang udang nol. Panjang asimptotik $\left(\mathrm{CL}_{\infty}\right)$ dan laju pertumbuhan $(\mathrm{K})$ diduga dengan metode ELEFAN dalam paket FISAT II (Gayanilo et al 2005). Nilai $t_{0}$ (umur pada saat panjang 0) diduga berdasarkan persamaan Pauly (1983) yaitu:

$\log \left(-\mathrm{t}_{0}\right)=(-0.3922)-0.2752 \log \mathrm{CL}_{\infty}-1.038 \log \mathrm{K}$

Mortalitas alami udang dianalisis berdasarkan persamaan Pauly et al. (1984) dengan penambahan temperatur rata-rata perairan $29^{\circ} \mathrm{C}$ :

$\log (\mathrm{M})=-0.0066-0.279 \log \left(\mathrm{L}_{\infty}\right)+0.6543 \log (\mathrm{K})+$

Mortalitas total $(\mathrm{Z})$ dianalisis berdasarkan kurva konversi panjang dengan hasil tangkapan (Length converted catch curve) dengan persamaan (Sparre \& Venema 1992):

$\ln =\frac{C(L 1, L 2)}{\Delta(L 1, L 2)}=C-Z * t\left(\frac{L 1+L 2}{2}\right)$

Di mana $\mathrm{Z}$ adalah total mortalitas, $\mathrm{C}$ adalah frekuensi udang pada setiap selang kelas, $\Delta \mathrm{t}$ adalah waktu yang diperlukan untuk tumbuh dari L1 ke L2, L1 adalah panjang pada umur $\mathrm{t}$ dan $\mathrm{L} 2$ adalah panjang pada umur $\mathrm{t}+\Delta \mathrm{t}$.

Mortalitas penangkapan (F) dan laju eksploitasi (E) diestimasi berdasarkan persamaan (Sparre \& Venema 1992):

$F=Z-M ; E=\frac{F}{Z}$

Estimasi rasio potensial pemijahan atau spawning potential ratio (SPR) diperoleh dengan metode berbasis data panjang (Length based SPR) (Hordyk et al., 2015). Data input yang digunakan dalam analisis SPR adalah rasio $\mathrm{M} / \mathrm{K}$, panjang karapas asimptotik $\left(\mathrm{CL}_{\infty}\right)$, proporsi $50 \%$ populasi matang gonad $\left(\mathrm{CL}_{50}\right)$, proporsi $95 \%$ populasi matang gonad $\left(\mathrm{CL}_{95}\right)$ dan panjang karapas udang. Estimasi rasio potensi pemijahan diperoleh berdasarkan perbandingan potensi pemijahan ketika dilakukan penangkapan $\left(S S B R_{\text {fished }}\right)$ dan ketika tidak dilakukan penangkapan $\left(S S B R_{\text {unfished }}\right)$ sebagaimana persamaan Goodyear (1993):

$$
S P R=\frac{S S B R_{\text {fished }}}{S S B R_{\text {unfished }}}
$$

\section{HASIL DAN BAHASAN \\ Hasil}

\section{Estimasi Parameter Pertumbuhan}

Ukuran panjang karapas dari 2.208 ekor sampel udang tiger yang tertangkap di perairan Tarakan berkisar antara 21,9-63 mmCL. Panjang karapas asimptotik $\left(\mathrm{CL}_{\infty}\right)$ diperoleh sebesar 65,45 $\mathrm{mm}$ dan koefisien pertumbuhan (K) sebesar 1,55 per tahun serta umur teoritis saat panjang ikan nol $\left(\mathrm{t}_{0}\right)$ sebesar $-0,20$ per tahun sehingga diperoleh persamaan pertumbuhan Von Bertalanffy CLt $=65,45(1-\mathrm{e}$ $-1,55(\mathrm{t}+-0,20)$ ) (Gambar 2 dan Gambar 3).

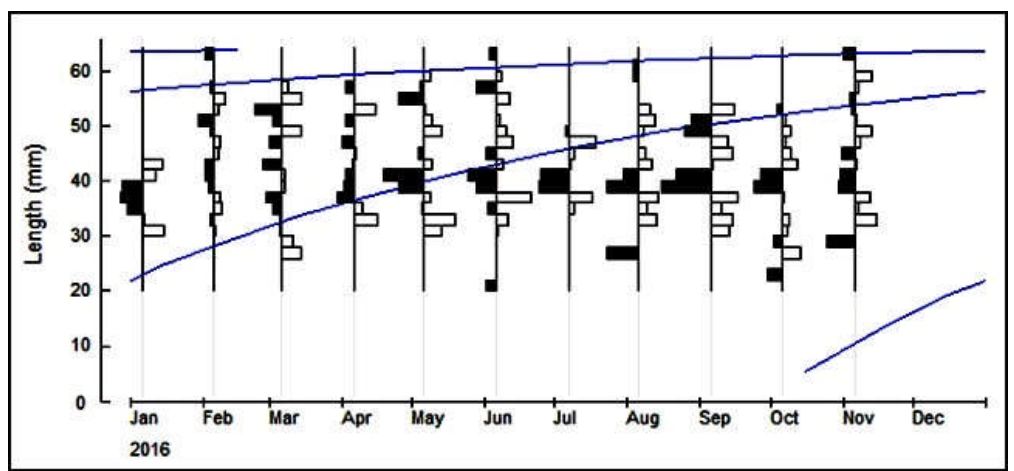

Gambar 2. Pertumbuhan udang tiger (P. monodon) di perairan Tarakan, tahun 2016.

Figure 2. Growth of tiger prawn (P. monodon) in Tarakan waters, 2016. 


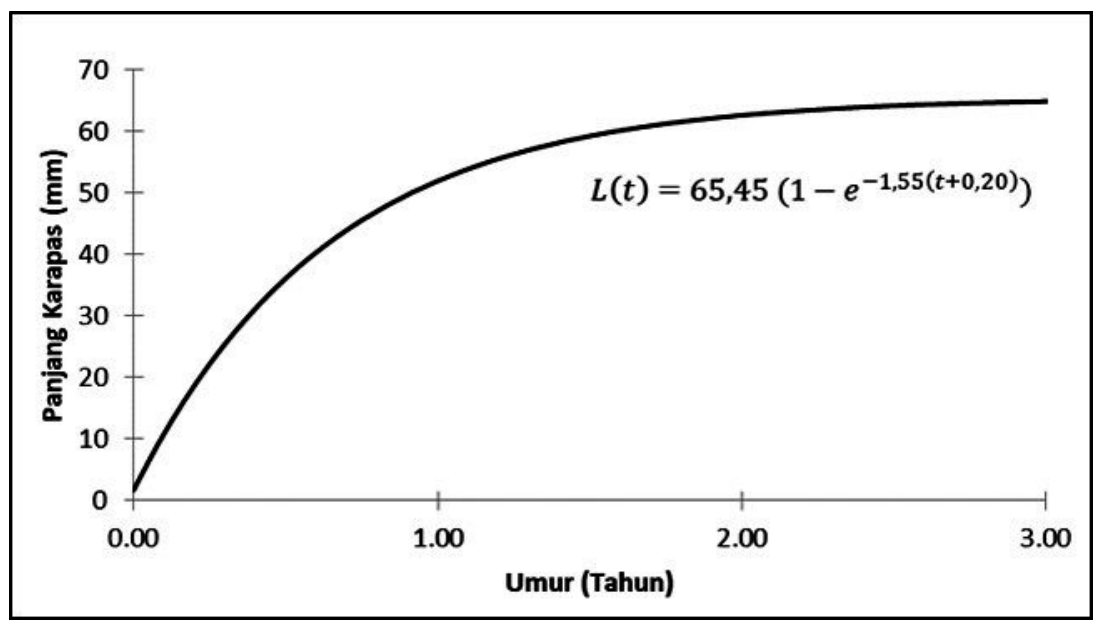

Gambar 3. Kurva Pertumbuhan Von Bertalanffy udang tiger (P. monodon) di perairan Tarakan, tahun 2016.

Figure 3. Von Bertalanffy Growth Curve of tiger prawn (P. monodon) in Tarakan Waters, 2016.

Laju Mortalitas Total (Z), Alami (M), Penangkapan (F) dan Laju Pemanfaatan (E)

Laju mortalitas total (Z) udang tiger (P. monodon) di perairan Tarakan diperoleh sebesar 6,56 per tahun. Ratarata suhu tahunan di perairan Tarakan sebesar $29^{\circ} \mathrm{C}$ sehingga jika dimasukkan dalam persamaan empiris Pauly et al., (1984) diperoleh laju mortalitas alami (M) dari udang tiger (P. monodon) adalah 1,95 per tahun. Laju mortalitas penangkapan $(\mathrm{F})$ udang tiger diperoleh sebesar 4,62 pertahun dengan laju eksploitasi (E) sebesar 0,70 pertahun.

\section{Pola Rekruitmen}

Pola rekruitmen udang tiger (P. monodon) di peraiaran Tarakan menunjukkan dua modus dalam satu tahun dengan puncak rekruitmen tertinggi terjadi pada bulan Mei dan Agustus (Gambar 4).

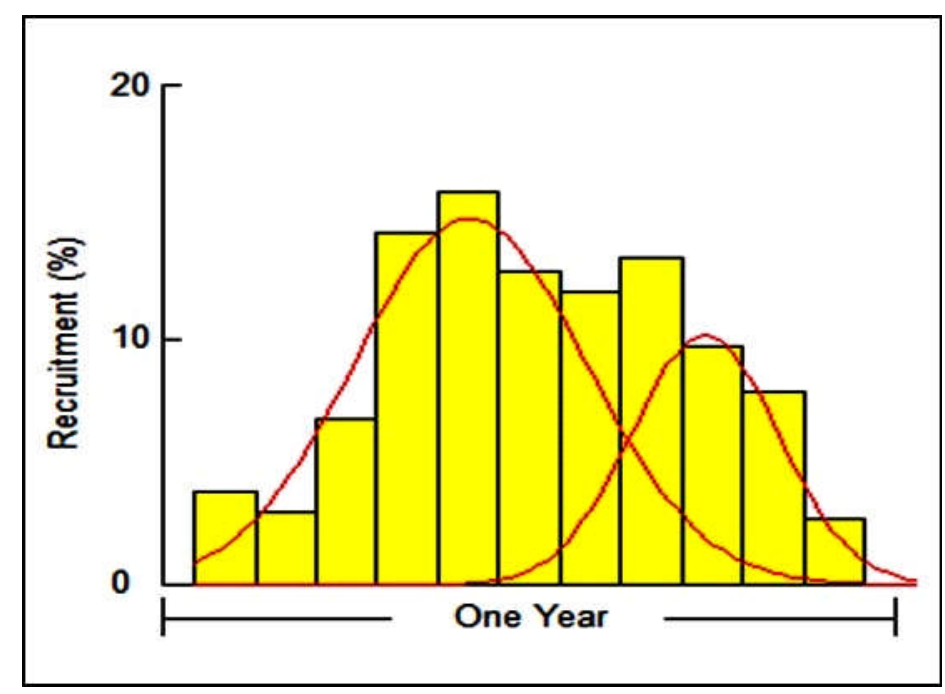

Gambar 4. Kurva pola rekruitmen udang tiger (P. monodon) di perairan Tarakan, tahun 2016.

Figure 4. Recruitmen pattern curve of tiger shrimp (P. monodon) in Tarakan waters, 2016.

\section{Rasio Potensi Pemijahan (Spawning Potential Ratio / $S P R)$}

Input data yang diperlukan dalam analisis LB-SPR adalah parameter pertumbuhan meliputi panjang $\operatorname{asimptotik}\left(\mathrm{CL}_{\infty}\right)$ dan laju pertumbuhan $(\mathrm{K})$, laju kematian alami (M) dan rata-rata pertama kali matang gonad (CLm). Panjang asimptotik udang tiger betina diperoleh sebesar
$65,45 \mathrm{mmCL}$, laju pertumbuhan $(\mathrm{K})$ sebesar 1,55 per tahun, laju kematian alami sebesar 1,95 per tahun dan rata-rata panjang pertama kali matang gonad (CLm) sebesar 33,58 mmCL (Chodrijah \& Faizah, 2018). Analisis estimasi rasio pemijahan berbasis data panjang $(L B-S P R)$ diperoleh rasio potensi pemijahan udang tiger di perairan Tarakan dan sekitarnya sebesar 0,30 atau sebesar $30 \%$. 


\section{BAHASAN}

Panjang karapas asimptotik $\left(\mathrm{CL}_{\infty}\right)$ udang tiger (Penaeus monodon Fabricius 1798) yang diperoleh pada penelitian ini adalah $65,45 \mathrm{mmCL}$ dengan laju pertumbuhan (K) sebesar 1,07 per tahun. Hasil yang diperoleh tersebut serupa dengan panjang karapas asimptotik dan laju pertumbuhan udang tiger (Penaues monodon) di perairan Selat Madura yang berkisar antara 67-68 mm dengan laju pertumbuhan berkisar antara 1,3-1,5 per tahun (Setyohadi et al., 1999), namun lebih kecil dibandingkan dengan hasil penelitian Kembaren \& Nurdin, (2013) di perairan Tarakan pada tahun 2012 sebesar 84,8 mmCL. Ukuran udang tiger saat ini lebih kecil dibandingkan beberapa tahun sebelumnya disebabkan penangkapan yang terus dilakukan di perairan pantai dan trammel net yang digunakan masih tergolong kurang selektif sehingga sebagian besar udang yang tertangkap belum mecapai ukuran optimal. Laju pertumbuhan $(\mathrm{K})$ udang tiger di daerah penelitian sebesar 1,55 per tahun lebih tinggi dibandingkan di perairan Sungai Andoni, Nigeria sebesar 0,87 per tahun (Komi et al., 2013). Perbedaan parameter pertumbuhan dapat disebabkan oleh perbedaan lama waktu, musim, ukuran ikan, alat tangkap yang digunakan dan daerah penangkapan pada saat sampling (Aziz et al., 1992). Mamie (2008) menambahkan bahwa parameter pertumbuhan dipengaruhi oleh variabilitas tingkat pertumbuhan setiap jenis kelamin, kelas umur dan musim yang berbeda. Selanjutnya Widodo (1988) menyebutkan bahwa adanya perbedaan nilai parameter pertumbuhan ini lebih dipengaruhi oleh komposisi jumlah contoh dengan cara atau metode yang digunakan.

Laju kematian total (Z) udang tiger di daerah penelitian sebesar 6,56/tahun, laju kematian alami (M) sebesar 1,95 per tahun dan laju kematian penangkapan (F) sebesar 4,62 per tahun. Hasil penelitian Kembaren \& Nurdin (2013) di perairan Tarakan tahun 2012 menunjukkan nilai laju kematian total $(Z)$ udang tiger sebesar 4,17 per tahun, nilai laju mortalitas alami (M) sebesar 1,85 per tahun dan laju mortalitas penangkapan (F) sebesar 2,32 per tahun. Laju kematian karena penangkapan udang saat ini tidak jauh berbeda dan cenderung lebih besar dibandingkan beberapa tahun sebelumnya menunjukkan belum adanya upaya untuk mengurangi tekanan penangkapan udang tiger di perairan Tarakan. Upaya penurunan tekanan penangkapan udang tiger di perairan Tarakan dapat menjadi alternatif pengelolaan perikanan udang yang berkelanjutan. Laju kematian alami udang tiger di perairan Tarakan lebih kecil dibandingkan di perairan Bushehr yaitu berkisar antara 2,11 - 2,41 per tahun (Niamaimandi, 2006). Kondisi tersebut menunjukkan bahwa kondisi lingkungan perairan di Tarakan masih lebih baik untuk perkembangan udang tiger dibandingkan di perairan Bushehr. Laju pengusahaan udang saat ini telah melebihi tingkat pemanfaatan optimal. Pauly et al. (1984) menyarankan yang rasional dan lestari di suatu perairan berada pada nilai $\mathrm{E}<0,5$ atau paling tinggi pada nilai $\mathrm{E}=0,5$. Berdasarkan hal tersebut dapat dikatakan bahwa tingkat pemanfaatan udang tiger diperairan Tarakan mengalami penangkapan yang sudah over fishing. Hal ini diperkuat oleh Kembaren \& Nurdin, (2013) yang menyebutkan bahwa tingkat pemanfaatan udang tiger di perairan Tarakan sudah jenuh bahkan cenderung mengarah pada penangkapan berlebih (over-fishing). Hal ini didukung oleh penelitian sebelumnya yaitu Chodrijah \& Faizah, (2018) yang menyatakan bahwa ukuran pertama kali matang gonad udang windu adalah $33,58 \mathrm{mmCL}$ dan ukuran rata-rata tertangkap adalah 40,69 mmCL, jika dilakukan penangkapan terus menerus menyebabkan over fishing.

Puncak rekruitmen udang tiger bervariasi pada beberapa perairan dipengaruhi oleh musim pemijahan. Rekruitmen udang tiger tertinggi ditemukan pada bulan Mei. Pola rekruitmen ini hampir sama dengan hasil penelitian Kembaren \& Nurdin, (2013) di lokasi dan spesies yang sama yaitu terjadi pada bulan Mei dan Juni begitu juga dengan di perairan Aceh yaitu April dan Agustus (Hedianto et al, 2016). Menurut Kannan et al., (2014), udang tiger di Pazhayar Tamil Nadu, bagian Tenggara pesisir India memijah pada Agustus-September dan Februari-Maret selama pre- dan postmonsoon dengan puncak pemijahan pada Maret dan Agustus. Selanjutnya Dall et al., (1990) menyatakan bahwa udang Penaeus mencapai usia muda (sub adult) kemudian masuk ke daerah penangkapan setelah sekitar $3-5$ bulan. Sehingga, diduga rekruitmen udang tiger di bulan Mei berasal dari pemijahan pada bulan Maret. Kembaren et al., (2013) menyatakan bahwa musim pemijahan udang windu di perairan ini cenderung tinggi pada bulan Maret dengan puncak pada bulan Juli.

Kisaran rasio potensi pemijahan di suatu perairan berkisar antara 0-100\% (Goodyear, 1993). Nilai SPR sebesar 0 terjadi pada kondisi tingkat pemanfaatan sumberdaya ikan yang telah penuh sedangkan nilai SPR $100 \%$ terjadi pada status pemanfaatan di bawah optimum atau perairannya masih alami (Hordyk et al., 2015; Brooks et al., 2010). Rasio potensi pemijahan didefinisikan sebagai sisa proporsi ikan tidak tertangkap yang berpotensi melakukan pemijahan di bawah tekanan penangkapan (Mace \& Sissenwine, 1993; Walters \& Martell, 2004; Prince et al., 2015). Estimasi rasio potensi pemijahan udang tiger di perairan Tarakan dan sekitarnya diperoleh sebesar 30\% menunjukkan terdapat sekitar $30 \%$ populasi udang tidak tertangkap yang berpotensi melakukan pemijahan. Rasio potensi pemijahan akan mengalami penurunan ketika tekanan penangkapan semakin meningkat (Goodyear, 1993). Ambang batas potensi rasio pemijahan yang optimal saat ini telah disarankan oleh Clark (2002) sebesar $40 \%$. Rasio potensi pemijahan udang tiger di perairan Tarakan saat ini masih lebih kecil dibandingkan rasio potensi 
pemijahan optimal sehingga penurunan upaya diharapkan dapat meningkatkan rasio potensi pemijahan udang di perairan Tarakan.

Mengingat bahwa ukuran udang yang tertangkap didominasi oleh udang udang muda maka pembatasan ukuran udang yang tertangkap ataupun pengaturan ukuran mata jaring disarankan untuk dilakukan agar udang tersebut mempunyai kesempatan melakukan proses reproduksi dan menambah rekruitmen.

\section{KESIMPULAN}

Parameter populasi udang tiger (Penaeus monodon) di perairan Tarakan dan sekitarnya menunjukkan laju pertumbuhan yang cepat, kematian alami kecil, dan kematian akibat penangkapannya tinggi. Pola rekruitmen udang tiger perairan Tarakan terjadi pada dua kali dalam setahun yaitu pada bulan Mei dan Agustus. Status pemanfaatan udang tiger sudah jenuh berdasarkan tingkat pemanfaatan (E) sebesar 0,70 per tahun dan estimasi rasio potensi pemijahan sebesar 0,30 .

\section{PERSANTUNAN}

Tulisan ini merupakan bagian dari kegiatan penelitian Karakteristik Biologi Perikanan, Habitat Sumber Daya Ikan dan Potensi Produksi Sumberdaya Perikanan di WPP716 (Laut Sulawesi dan sebelah Utara Pulau Halmahera) pada Balai Penelitian Perikanan Laut Muara Baru, Jakarta Tahun Anggaran 2016. Penulis juga mengucapkan terima kasih kepada petugas enumerator di Tarakan yang telah membantu dalam pengumpulan data selama penelitian.

\section{DAFTAR PUSTAKA}

Brooks, E. N., Powers, J. E., \& Cortes, E. (2010). Analytical reference points for age-structured models: application to data-poor fisheries. ICES Journal of Marine Science, 67, 165 - 175.

Chodrijah, U., \& Faizah, R. (2018). Beberapa aspek biologi udang windu (Penaeus monodon (Fabricus 1789) di perairan Tarakan, Kalimantan Utara. BAWAL. 10 (1): 49-55 http://dx.doi.org/10.15578/bawal.10.1.2018.49-55.

Clark, W. G. W. (2002). $\mathrm{F}_{35 \%}$ revisited ten years later. North American Journal of Fisheries Management, 22: 251257 https://doi.org/10.1577/1548-8675 (2002)022\%3C0251:FRTYL\%3E2.0.CO;2.

Dall, W., Hill, B.J., Rothlisberg, P.C., \& Staples, D.J. (1990). The Biology of the Penaeidae.In Advances in Marine Biology, Vol. 27, edited by J. H. S. Blexter and A. J. Southward. Academic Press, London. 489 p.
Direktorat Jenderal Perikanan Tangkap. (2016). Statistik Perikanan Tangkap Indonesia menurut Provinsi 2016. Direktorat Jenderal Perikanan Tangkap.

Gayanilo, F. C. Jr., Sparre, P., \& Pauly, D. (2005). FAOICLARM Stock Assessment Tools II (FISAT II). Revised version. User's guide. FAO Computerized Information Series (Fisheries) No. 8. Revised Version. FAO Rome.

Goodyear, C. P. (1993). Spawning stock biomass per recruit in fisheries management: foundation and current use. (p. 67-81). In S. J. Smith, J.J. Hunt and D. Rivard (ed). Risk evaluation and biological reference points for fisheries management. Can. Spec. Publ. Fish. Aquat. Sci. 120 pp.

Hedianto, D. A., Suryandari, A. S., \& Tjahjo, D. W. H. (2016). Dinamika populasi dan status pemanfaatan udang windu Penaeus monodon (Fabricius, 1789) di perairan Aceh Timur, Provinsi Aceh. J. Lit. Perikan. Ind. 22(2), 71-82. http://dx.doi.org/10.15578/ jppi.22.2.2016.71-82

Hordyk, A., Ono, K., Valencia, S., Loneragan, N., \& Prince, J. (2015). A novel length-based empirical estimation method of spawning potential ratio (SPR), and tests of its performance, for small-scale, data-poor fisheries. ICES Journal of Marine Science, 72(1), 217-231.doi : 10.1093/icesjms/ fsu004.

Kannan, D., Jagadeesan, K., Shettu, N., \& Thirunavukkarasu, P. (2014). Maturation and spawning of commercially important Penaeid Shrimp Penaeus monodon Fabricius at Pazhayar Tamil Nadu (South East Coast of India). Journal of Fisheries and Aquatic Science. 9(4), 170-175. doi : 10.3923/jifas.2014.170-175.

Kembaren, D. D., \& Nurdin, E. (2013). Dinamika populasi dan tingkat pemanfaatan udang windu (Penaeus mondon) di perairan Tarakan, Kalimantan Timur. J. Lit. Perikan. Ind. 19(4), 221-226. http://dx.doi.org/10.15578/ jppi.19.4.2013.221-226.

Komi, G. W., Francis, A., \& Aleleye-Wokoma, I. P.(2013). Mortality and exploitation of Penaeus monodon in the Andoni River, Nigeria. J. Nat. Sci.Res., (15), 58-67 https://iiste.org/Journals/index.php/JNSR/article/ view/9717/9930.

Mace, P. M., \& Sissenwine, M. P. (1993). How much spawning per recruit is enough? In S.J. Smith, J.J. Hunt and D. Rivard (eds.) Risk evaluation and biological reference points for fisheries management. Canadian Special Publications in Fisheries and Aquatic Sciences, 120, 101-118. 
Mamie, Josephus Choe Junior. (2008). Stock Assessment of Shrimp Pandalus borealis (Krøyer 1838) in Skjálfandi Bay Northern Iceland. Final Project 2008 UNU - Fisheries Training Programme.

Niamaimandi, N. (2006). Bio-dynamics and life cycle of shrimp (Penaeus semisulcatus de Haan), in Bushehr coastal waters of the Persian Gulf. Ph.D. Thesis, 206 p. Univ. Putra Malaysia, Kuala Lumpur, Malaysia.

Pauly, D. (1983). Some Simple Methods for the Assessment of Tropical Fish Stocks. FAO Fisheries Technical Paper, 254, 52.

Pauly, D., Ingles, J., \& Neal, R. (1984). Application to shrimp stocks of objective methods for the estimation of growth, mortality and recruitment-related parameters from legth-frequency date (ELEFAN I and II). Penaeid shrimps-Their biology and management. Fishing News Books Ltd. 308 pp

Prince, J., Victor, S., Kloulchad, V., \& Hordyk, A. (2015). Length based SPR assessment of eleven Indo-Pacific coral reef fish populations in Palau. Fisheries Research, 171, 42-58. http://dx.doi.org/10.1016/ j.fishres.2015.06.008
Setyohadi, D., Nugroho, D., Lelono, T. J., Wiadnya, D. G. R., \& Martinus. (1999). Biologi dan distribusi sumberdaya udang penaeid berdasarkan hasil tangkapan di Selat Madura. Laporan Penelitian Litbang Pertanian, 50 - 61.

Sparre, P., \& S. C. Venema. (1992). Introduksi pengkajian stok ikan tropis. Buku I: Manual. Diterjemahkan oleh Pusat Penelitian dan Pengembangan Perikanan.Organisasi Pangan dan Pertanian. Perserikatan Bangsa-Bangsa. Jakarta. Indonesia. Xiv: 438.

Walters, C., \& Martell, S. J. D. (2004). Fisheries ecology and management. Princeton University Press, Princeton, NJ. 399 pp.

Widodo, J. (1988). Population dynamics and management of Ikan Layang, Scad Mackerel, Decapterus spp. (Pisces: Carangidae) in the Java Sea. Ph.D. Dissertation. Univ. Wash. Seattle. 150 p. 